\title{
The lead leads the way
}

\author{
S. Borges $(1 D)$ J. I. Moreira
}

Accepted: 21 July 2021 / Published online: 27 August 2021

(C) The Author(s) 2021

An 86-year-old diabetic and hypertensive female with permanent atrial fibrillation (AF) presented to the emergency department with recurrent pre-syncope and one episode of syncope. The baseline electrocardiogram showed AF with a ventricular rate of 47 beats/min. Holter monitoring confirmed AF with a slow ventricular rate. The patient was then referred for single-chamber pacemaker implantation but the procedure was not uneventful. Fig. 1 shows the final position of the lead at the end of the procedure. What is the most likely diagnosis?

\section{Answer}

You will find the answer elsewhere in this issue.

Conflict of interest S. Borges and J.I. Moreira declare that they have no competing interests.

Open Access This article is licensed under a Creative Commons Attribution 4.0 International License, which permits use, sharing, adaptation, distribution and reproduction in any medium or format, as long as you give appropriate credit to the original author(s) and the source, provide a link to the Creative Commons licence, and indicate if changes were made. The images or other third party material in this article are included in the article's Creative Commons licence, unless indicated otherwise in a credit line to the material. If material is not included in the article's Creative Commons licence and your intended use is not permitted by statutory regulation or exceeds the permitted use, you will need to obtain permission directly from the copyright holder. To view a copy of this licence, visit http://creativecommons.org/licenses/by/4.0/.

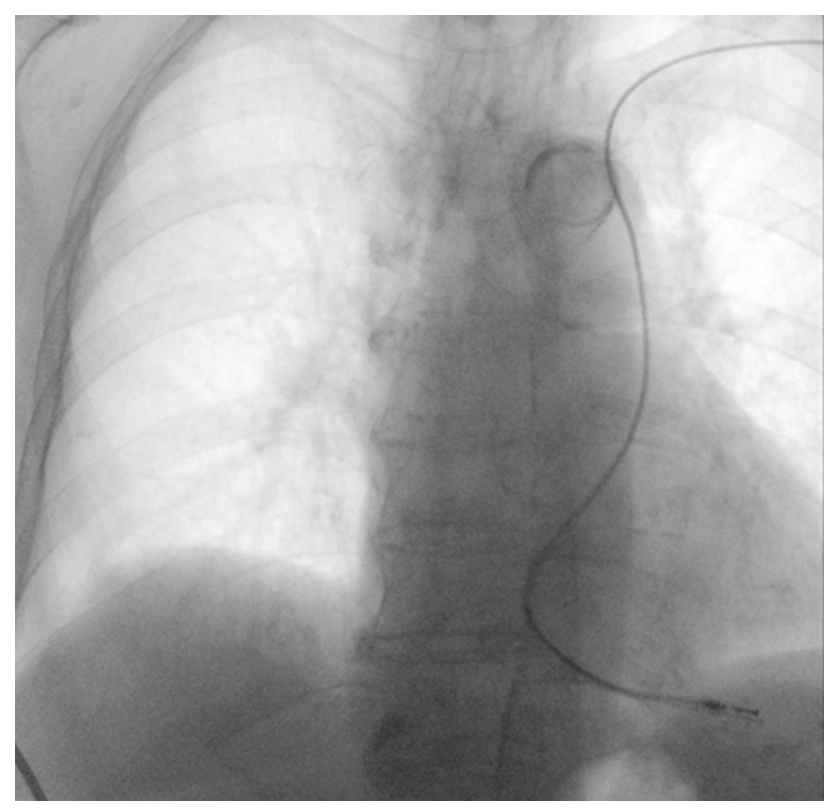

Fig. 1 Position of the lead following single-chamber pacemaker implantation

\footnotetext{
S. Borges $(\bowtie) \cdot$ J. I. Moreira

Cardiology Department, Centro Hospitalar de Trás os

Montes e Alto Douro, Vila Real, Portugal

saracs.borges@gmail.com
} 